\title{
BIOGRAFIAS NÃO AUTORIZADAS CONFLITO ENTRE A LIBERDADE DE EXPRESSÃO E A INVIOLABILIDADE DA INTIMIDADE
}

\author{
Bernardo Silva de Seixas ${ }^{1}$ \\ Roberta Kelly Silva Souza ${ }^{2}$
}

\begin{abstract}
Resumo
A temática abordada neste ensaio diz respeito ao conflito de direitos fundamentais, de um lado o direito a liberdade de expressão e do lado oposto o direito a inviolabilidade da vida privada. Debruça-se sobre esta temática em razão de existir no ordenamento jurídico pátrio controvérsia a respeito de tentativa de publicações de biografias não autorizadas de personalidade públicas por biógrafos, fato que causa desavenças entre particulares e que deve ser pacificada pelo Poder Judiciário. Neste ínterim, aborda-se a questão dos direitos fundamentais de liberdade de expressão e inviolabilidade da vida privada na Constituição Federal de 1988, questionando-se a questão da aplicabilidade dos direitos fundamentais nas relações privadas. Estuda-se a ação direta de inconstitucionalidade em trâmite no Supremo Tribunal Federal a respeito da problemática suscitada já que há argumentação jurídica no sentido que o Código Civil detem dispositivo que possivelmente afronte o direito de liberdade de expressão, bem como critica-se a decisão tomada pelo Supremo Tribunal Federal. A metodologia aplicada ao trabalho fora a dedutiva, com análise da jurisprudência e doutrina sobre o caso em análise.
\end{abstract}

Palavras-Chave: Liberdade de Expressão; Vida Íntima; Direitos Fundamentais; Proporcionalidade.

\section{INTRODUÇÃO}

A Constituição Federal de 1988 (CF/88) é marcada, principalmente, pela ampla gama de direitos fundamentais concedidos aos indivíduos que visam proteger, sendo esta uma de suas variadas funções, o indivíduo contra atos do Estado que possam lhe causar prejuízos a sua dignidade. Neste ínterim, o legislador originário previu inúmeros direitos que, em determinadas situações fáticas e considerando a complexidade da sociedade atual, entram em conflito, sendo um exemplo a questão da liberdade de expressão e a inviolabilidade da vida privada, não olvidando de outras miscelâneas que podem ocorrer no seio social.

\footnotetext{
${ }^{1}$ Mestre em Direito Constitucional pela Instituição Toledo de Ensino. Pós-Graduando em Giustizia Costituzionale e Tutela Giurisdizionale pela Universitá di Pisa, UNIPI, Itália. Especialista em Direito Processual pelo Centro Universitário de Ensino Superior do Amazonas. Professor de Direito Civil na Universidade Federal do Amazonas. Professor de Processo Civil no Centro Universitário de Ensino Superior do Amazonas. E-mail: seixas.bernardo@gmail.com

${ }^{2}$ Mestre em Direito Constitucional pela Instituição Toledo de Ensino. Especialista em Direito Processual e Direito Público pelo Centro Universitário de Ensino Superior do Amazonas. Especialização em andamento em Giustizia Costituzionale e Tutela Giurisdizionale na Universitá di Pisa, UNIPI, Itália. E-mail: rkellyss@yahoo.com.br
} vol.09, nº. 01, Rio de Janeiro, 2016.pp. 441-459 
O presente trabalho trata sobre uma questão fática que se discute no âmbito do Supremo Tribunal Federal (STF) que se refere a divulgação, edição e comercialização de biografias de personalidades públicas sem que tenha havido a devida autorização do indivíduo que tem sua vida relatada numa obra comercial, tal qual previsto nos arts. 20 e 21, Código Civil (CC). A controvérsia jurídica surgiu na mídia - ganhando proporções inimagináveis - quando o cantor Roberto Carlos recorreu ao Poder Judiciário para obstar a venda de um livro com o título "Roberto Carlos em Detalhes" escrito pelo jornalista Paulo Cesar de Araújo que relatava inúmeros fatos de sua vida particular, baseados em depoimentos e entrevistas de terceiros, sem que tenha havido a concessão de autorização para realização da obra pela personalidade pública ou, ao menos, a participação do biografado.

Portanto, a temática central deste ensaio se refere a questão da denominada censura privada, que obsta a publicação de obras sem a autorização do biografado e, consequentemente, o direito de liberdade de expressão dos biógrafos em relatar a vida de uma personalidade pública que influencia na sociedade.

Destarte, justifica-se a presente temática em virtude de haver conflitos a respeito de escritores/jornalistas interessados em vender obras que versem sobre assuntos íntimos de personalidades públicas de todas as estirpes, sem ao menos haver a preocupação se aquela pessoa, mesmo que usufrua do contato com o público e se beneficie financeiramente com esta interação, tenha determinados assuntos restritos à sua esfera particular que não deseja tornar público, seja por qual razão for.

Da temática abordada surge os seguintes questionamentos: Como o ordenamento jurídico brasileiro trata da questão das biografias não autorizadas? A comercialização de biografias não autorizadas afronta o direito da intimidade? A liberdade de expressão pode ultrapassar os limites da intimidade quando o indivíduo é personalidade pública renomada? Há algum meio técnico jurídico que se possa valer o Poder Judiciário para resolver este conflito sem que ocorra prejuízo para algum dos direitos fundamentais conflitantes? Qual a posição do Supremo Tribunal Federal sobre esta temática?

Portanto, o objetivo geral deste trabalho é verificar se a posição que o Supremo Tribunal Federal tomou em relação ao conflito existente entre o direito de liberdade de expressão/informação e o da inviolabilidade da vida privada foi a mais adequada constitucionalmente. Outrossim, os objetivos específicos são tratar sobre os direitos fundamentais no Constituição Federal e sua aplicabilidade nas relações privadas, assim como se debruçar sobre a Ação Direta de Inconstitucionalidade (ADI) n. 4.815, em trâmite no STF, demonstrando quais são os argumentos apontados a favor ou contra a obrigatoriedade de autorização do biografado para publicação de fatos de sua vida íntima, bem como analisar a decisão do Plenário do Supremo Tribunal Federal sobre esta questão.

Para tanto, visando cumprir com os questionamentos alhures suscitados e alcançar os objetivos propostos, por intermédio de pesquisa bibliográfica e jurisprudencial, orientando-se pelo método de pesquisa dedutivo, partindo-se de uma premissa maior (conflito entre intimidade e liberdade de expressão) para abordar a 
premissa menor (questão da necessidade de autorização para biografias no ordenamento jurídico brasileiro), aborda-se no primeiro capítulo a temática referente aos direitos fundamentais relacionados com a questão da liberdade de expressão e do direito à intimidade no ordenamento jurídico brasileiro, bem como sobre a aplicabilidade dos direitos fundamentais nas relações privadas.

Em um segundo momento, aborda-se a questão da ação direta de inconstitucionalidade ajuizada no órgão de cúpula do Poder Judiciário brasileiro para pacificar a controvérsia a respeito da constitucionalidade ou não dos arts. 20 e 21 do Código Civil, informando os argumentos jurídicos e fáticos de ambos os lados sobre esta temática, bem como dissertando sobre as particularidades da Jurisdição Constitucional que estão sendo aplicadas nesta ação direta de inconstitucionalidade. Por fim, ainda neste tópico, faz-se uma crítica ao posicionamento adotado pelo Supremo Tribunal Federal no julgamento da ação do controle concentrado que trata a respeito do conflito entre a liberdade de expressão e o direito à proteção da vida privada.

Posteriormente, apresenta-se uma proposição, com auxílio do critério da proporcionalidade, para resolver o conflito entre princípios constitucionais visando uma resposta constitucionalmente adequada para a compatibilização dos princípios conflitantes, sendo benéfica para que todos os indivíduos, independentemente da atividade que exerça, assim como para os biógrafos e editoras, possam usufruir dos direitos fundamentais contidos na Constituição Federal sem qualquer interferência ou afronta aos direitos relacionadas à vida privada da personalidade pública.

\section{O DIREITO FUNDAMENTAL A LIBERDADE DE EXPRESSÃO E A PROTEÇÃO DA INTIMIDADE NA ORDEM CONSTITUCIONAL BRASILEIRA E SUA APLICABILIDADE HORIZONTAL NAS RELAÇÕES PRIVADAS}

Os direitos fundamentais são previsões, normalmente constitucionais, que permitem que a pessoa humana exerça sua vontade na sociedade, que atue sem interferências estatais, desde que esta atuação respeite os limites impostos pelos direitos de outrem. Se desenvolveram juntamente com a sociedade, sendo renovados ou criados dependente das circunstancias fáticas que surgem com a evolução social e tecnológica. Não se pode precisar suas origens, mas detêm, atualmente, relevância internacional com inúmeras assinaturas de tratados internacionais que impõem a observância pelos Estados signatários, havendo, inclusive, tribunais internacionais que julgam Estados ou pessoas que desrespeitam, reiteradamente, as disposições fundamentais da pessoa humana.

Nesse sentido, faz-se necessário mencionar que os Direitos Fundamentais, não surgiram a partir do pensamento dos legisladores, mas sim, através de conquistas humanitárias, que foram aos poucos inseridas aos ordenamentos jurídicos dos diversos países e, reconhecidos e constitucionalizados pelos legisladores. 
Pode-se citar inúmeros preceitos que permitem o desenvolvimento humano sem interferências estatais, o direito à propriedade, à vida, liberdade, dentre inúmeros outros previstos em Constituições e convenções internacionais. A atual Constituição Federal brasileira é reconhecidamente um documento garantista em relação aos direitos fundamentais, neste sentido leciona Ingo Sarlet (2012, p. 63-64)

Traçando-se um paralelo entre a Constituição de 1988 e o direito constitucional positivo anterior, constata-se, já numa primeira leitura, a existência de algumas inovações de significativa importância na seara dos direitos fundamentais. De certo modo, é possível afirmar-se que, pela primeira vez na história do constitucionalismo pátrio, a matéria foi tratada com a merecida relevância. [...] Três características consensualmente atribuídas à Constituição de 1988 podem ser consideradas (ao menos em parte) como extensivas ao título dos direitos fundamentais, nomeadamente seu caráter analítico, seu pluralismo e seu forte cunho programático e dirigente.

Os Direitos Fundamentais não estão enumerados apenas no Título II da Constituição Brasileira, mas estão presentes em toda a Constituição, como exemplo temos o direito à saúde. Tais direitos destinam-se a todos os indivíduos independentemente de sua nacionalidade ou situação no Brasil. Assim, até mesmo um estrangeiro não residente no país é destinatário da proteção constitucional. De acordo com Araujo e Nunes Junior (2013, p. 153)

Os Direitos Fundamentais constituem uma categoria jurídica, constitucionalmente erigida e vocacionada à proteção da dignidade humana em todas as dimensões. Destarte, possuem natureza poliédrica, prestando-se ao resguardo do ser humano na sua liberdade (direitos e garantias individuais), nas suas necessidades (direitos econômicos, sociais e culturais) e na sua preservação (direitos à fraternidade e à solidariedade)

Neste diapasão o Constituinte originário previu diversos direitos aos indivíduos que compõem o Estado brasileiro que se aplicam a inúmeros fatos jurídicos que ocorrem na sociedade. Na questão referente às biografias não autorizadas há dois direitos fundamentais suscitados pelas partes antagonistas, quais sejam, a liberdade de expressão e a inviolabilidade da vida privada, ambos com sede constitucional nos arts. $5^{\circ}$, IV, V, X, IX, XIV e 220, $\mathrm{CF} / 88$.

A liberdade de expressão é considerada um direito fundamental de primeira dimensão, haja vista que seu exercício decorre de uma abstenção do Poder Estatal, encontra-se prevista desde a Constituição de 1822 no ordenamento jurídico pátrio. Seu conteúdo, na esteira de Paulo Branco (MENDES e BRANCO, 2012, p. 299), compreende "A garantia da liberdade de expressão tutela [...] toda opinião, convicção, comentário, avaliação ou julgamento sobre qualquer assunto ou sobre qualquer pessoa, envolvendo tema de interesse público, ou não, de importância e de valor, ou não [...]”.

Destarte, se expressar faz parte da natureza humana, seja de que maneira for e para que finalidade. Desde quando o Homem criou as formas de se comunicar veem se expressando, seja consigo mesmo, com pessoas de sua comunidade ou com diversas culturas com o escopo de transmitir uma mensagem ou um conhecimento, seja por meio da linguagem - escrita ou oral - ou por intermédio de sinais, pinturas, desenhos, permitindo o desenvolvimento da sociedade e a propagação do conhecimento que propicia o desenvolvimento social e vol.09, nº. 01, Rio de Janeiro, 2016.pp. 441-459 
modifica o comportamento humano. Portanto, este direito é inato à condição humana do Homem, não havendo possibilidade, em um Estado que observe a dignidade humana, a imposição de limites, tais como a censura, ao direito de manifestação do indivíduo.

Outrossim, o exercício do direito de expressão é fundamental para a consolidação do Estado Democrático, pois somente com a circulação de informações livres, que tratam a respeito de investigações e denuncias, por meio do trabalho de uma imprensa sem restrições ou comprometimentos, sobre os atos, compatíveis ou não com a vontade popular dos agentes públicos, podem formar e modificar a opinião pública contra a propaganda oficial do governo, proporcionando e elevando a participação democrática nos assuntos estatais. Corrobora este entendimento a lição de Nicole Gonçalves (2014, p. 392)

A liberdade de expressão é "ponto de partida" para qualquer proposta de democracia que pretende aprofundar e ampliar o debate na esfera pública. Sem liberdade de expressão não há diálogo público e inviabiliza-se a formação de uma opinião pública. Ademais, a liberdade de expressão é o direito fundamental que possibilita o exercício da soberania popular e pelo qual se concretizam as virtudes republicanas, uma vez que torna os cidadãos capazes de escolher, fiscalizar, contestar e exigir o devido exercício dos Poderes Públicos.

Ademais, cita-se o entendimento de que o direito de liberdade de expressão tem posição privilegiada na Constituição Cidadã com preferência em relação a outros direitos fundamentais, em que pese não haver hierarquia entre os mesmos, pois, conforme anteriormente mencionado, a partir do exercício do direito de liberdade de expressão se pode exercer ou adquirir outros direitos fundamentais, tais como o pleno exercício da democracia, sufrágio e autogoverno. Complementa este posicionamento a lição de Rafael Lorenzo-Fernandez Koatz (2011, p. 401-402)

A doutrina vem desenvolvendo a teoria de que as liberdades de expressão e de imprensa situam-se em uma posição privilegiada dentro da Constituição. Essa posição axiologicamente mais elevada se deve ao fato de que as liberdades de expressão e de imprensa, a um só tempo, permitem o desenvolvimento de atributos inerentes à pessoa humana, bem como servem de instrumento para o exercício de outros direitos fundamentais.

Todavia, mesmo com sua fundamental importância para a sociedade nenhum direito fundamental é absoluto, há sim determinados limites que o direito de expressão deve observar sob pena de agredir diversos direitos fundamentais. As limitações podem ser veiculadas de forma expressa ou implícita. As restrições implícitas decorrem da interpretação constitucional sistemáticas, podendo-se citar a questão das manifestações de expressão que sejam impróprias para crianças e adolescentes. Sobre esta temática Gilmar Ferreira Mendes (MENDES E BRANCO, 2012, p. 307-308) leciona que:

A liberdade de expressão [...] poderá sofrer recuo quando o seu conteúdo puser em risco uma educação democrática, livre de ódios preconceituosos e fundada no superior valor intrínseco de todo ser humano. A liberdade de expressão, num contexto que estimule a violência e exponha a juventude à exploração de toda sorte, inclusive comercial, tende a ceder ao valor prima facie prioritário da proteção da infância e da adolescência. 
Entretanto, há algumas situações de relevo que a própria Constituição Federal prevê, expressamente, algumas restrições ao exercício pleno da liberdade de expressão com restrições à publicidade de bebidas alcóolicas, tabaco, medicamentos e terapias (art. 220, $₫ 4^{\circ}, \mathrm{CF} / 88$ ), a imposição de que determinadas manifestações do direito livre de expressão sejam realizadas em faixa etária compatível com a mensagem abordada pelo periódico ou filme cinematográfico (art. 220, $₫ 3^{\circ}, \mathrm{CF} / 88$ ), dentre outras normas expressas que impossibilitam de que o individuo divulgue sua opinião de maneira a afrontar direitos fundamentais de outrem.

Há ainda a limitação, implícita, imposta dele direito à inviolabilidade da vida privada à liberdade de expressão, ao qual interessa para este ensaio. $O$ direito a inviolabilidade da vida privada é um gênero que abrange diversos dispositivos constitucionais, sejam relacionados à inviolabilidade de domicílio, de correspondência, da imagem e da própria intimidade e privacidade. Walter Claudius Rothenburg (2014, p. 153) destaca sobre esses direitos fundamentais o seguinte

Privacidade (vida privada) e intimidade podem ser distinguidas em função do âmbito de abrangência e da intensidade. Assim, a privacidade corresponderia a uma esfera mais ampla (trabalho, família...), enquanto a intimidade, a uma esfera mais restrita. Fundamentalmente, porém, o direito é o mesmo, e o sujeito é que estabelece em que medida exerce seu direito [...]

É uma proteção que detem a pessoa humana contra a intromissão indevida em seus segredos ou em fatos que lhe causem determinado constrangimento que o indivíduo deseja omitir da opinião pública, da família e de terceiros, devendo-se respeitado pelo Estado e pelo particulares, haja vista que fatos íntimos pertencem a esfera pessoal de cada pessoa, não podendo ser propagados para terceiros, principalmente, se forem veiculadas com intuitos depreciativos, difamatórios, caluniosos ou com finalidade econômica.

No cenário sobre as biografias não autorizadas há, de fato, possibilidade de afronta aos direitos de inviolabilidade da vida íntima do biografado, pois existem fatos da vida da personalidade pública que ultrapassa seus interesses pessoais, sendo de interesse também público um fato particular que possa ter influenciado em determinado aspecto da vida social. Sobre este conflito são as didáticas palavras de Anderson Schreiber (2013, p. 456-457)

Não há qualquer vedação genérica no direito brasileiro à publicação de biografias não autorizadas. O que há, nos termos do Código Civil e de toda a tradição jurídica brasileira, é a proteção do direito à privacidade. Todas as pessoas, famosas ou não, tem direito à privacidade, entendida nesse particular como o direito de manter a salvo do público certos aspectos da sua vida íntima e pessoal. [...]. A pessoa privada, por definição, tem direito a manter longe dos olhos do público aspectos da sua vida íntima. Por outro lado, a Constituição brasileira protege a liberdade de expressão artística e intelectual (art. $5^{\mathrm{a}}$, IX). Como legítimo exercício dessa liberdade constitucional, um diretor pode decidir fazer um filme ou um escritor pode decidir elaborar uma biografia sobre uma celebridade. Para isso, o biógrafo pode se limitar a reunir e reapresentar ao público, de alguma forma, a trajetória pública do biografado [...]. Nesse caso, não há qualquer colisão entre a privacidade e a liberdade de expressão. Na maior parte das vezes, contudo, o biógrafo adentra (e é natural que adentre) a vida privada do biografado para apresenta-la ao público em alguma medida. É 
aí que o conflito se instaura: o biografado pode não querer ver divulgados aos leitores certos detalhes da sua trajetória.

Um fato relevante sobre o direito à inviolabilidade da vida privada é o fato de que este direito fundamental tem uma aplicação diferenciada para cada indivíduo, pois dependendo de determinadas variáveis, tais como profissão ou exercício de cargo público, há uma redução no âmbito de sua privacidade, pois seus atos são importantes para a vida da comunidade, no entanto, deve-se atentar para esta maleabilidade não ser levada ao extremo, pois não se pode reduzir demais o direito à intimidade desses indivíduos, sob pena supressão total deste direito, fato que deve ser evitado, haja vista que mesmo reduzido deve permanecer um núcleo existencial mínimo do direito fundamental. Sobre esta questão Walter Claudius Rothenburg (2014, p. 154) leciona

As pessoas famosas, especialmente os artistas que buscam e se beneficiam da notoriedade, expõem-se deliberadamente e provocam um interesse maior no público em geral. $\mathrm{O}$ âmbito de sua privacidade e seu direito de imagem são parcialmente diminuídos e protegidos com menos rigor que o das pessoas comuns. Ainda assim, é certo que o direito à reserva não desaparece e depende muito do contexto para se configurar.

Necessário frisar que esta controvérsia existente entre biógrafos e biografados ocorre em no âmbito exclusivo das relações privadas, sendo suscitados preceitos de direitos fundamentais contra os atos privados de publicação de biografia não autorizada para a defesa dos direitos da personalidade pública. Neste cenário, surge a teoria jurídica que determina a aplicação das normas de direitos fundamentais às relações privadas, fato que modifica a dogmática da teoria dos direitos fundamentais que defendem a aplicação desses direitos somente para a defesa do individuo contra atos dos agentes públicos e não contramanifestações de vontade de particulares.

A denominada eficácia horizontal de direitos fundamentais, também conhecida na Alemanha como Drittwirkung, é uma evolução da aplicabilidade da teoria dos direitos fundamentais. Sua principal característica é que também os particulares devem, quando exercerem seus próprios atos de vontade, observarem toda a gama de direitos fundamentais da pessoa humana, servindo, esses não somente contra atos do poder público, mas também nas relações privadas que em algumas circunstâncias, como nas relações de consumo, são tão desproporcionais quanto a relação Estado-pessoa, ampliando a eficácia protecional do individuo em todos os âmbitos de suas relações intersubjetivas. Sobre esta temática corrobora o escólio de José Adércio Leite Sampaio (2012, p. 654)

Os direitos fundamentais não são oponíveis apenas ao Estado, mas se aplicam também aos particulares, exigindo-lhes respeito e atenção. Sua eficácia, portanto, não se restringe aos domínios constitucionais, valendo, externamente, para os demais subsistemas jurídicos, por meio de relações intersubjetivas verticais (sujeitos privados e Estado) e horizontais (entre sujeitos privados). [...]. Indivíduos, sociedade e Estado são consorciados na política de realização jusfundamental.

Há inúmeras correntes doutrinárias que apontam como se devem aplicar os direitos fundamentais nas relações privadas, tais como as teorias de eficácia imediata e direta, da eficácia mediata e indireta, dentre outras doutrinas que visam tão somente compatibilizar pontos positivos de cada doutrina antagônica, contudo, em que pese as críticas, o Supremo Tribunal Federal tem adotado, segundo posicionamento de Leonardo Martins (DIMOULIS e MARTINS, 2012, p. 108), que a aplicação dos direitos fundamentais às relações privadas ocorre vol.09, n. 01, Rio de Janeiro, 2016. pp. 441-459 
de maneira direta, tal posicionamento decorre dos julgamentos dos seguintes Recursos Extraordinários (RE) 158.215 e 201.819 e tem como fundamento o art. $5^{\circ}, 1^{\circ}, \mathrm{CF} / 88$.

Destarte, verificada a importância dos direitos fundamentais na atual Constituição brasileira, a previsão dos direitos à liberdade de expressão e inviolabilidade da intimidade, bem como a possibilidade de aplicação direta desses direitos fundamentais às relações privadas, aborda-se a ação direta de inconstitucionalidade em trâmite no STF que discute a constitucionalidade dos arts. 20 e 21 do Código Civil.

\section{A JURISDIÇÃO CONSTITUCIONAL COMO ARENA PARA RESOLUÇÃO DE CONFLITOS ENTRE DIREITOS FUNDAMENTAIS. A DECISÃO DA ADI 4.815 PELO SUPREMO TRIBUNAL FEDERAL}

Inicialmente, deve-se mencionar que em que pese a controvérsia tenha sede constitucional detém fundamento também na seara do Direito Civil, já que se visa interpretar os arts. 20 e 21 daquela Lei Ordinária de maneira compatível com a Constituição, o que faz surgir a doutrina do Direito Civil Constitucional, que defende uma interpretação diferenciada desta codificação legal em consonância com os ditames e previsões constitucionais. Assim leciona Carlos Alberto Bittar (2003, p. 25-26)

A nova carta estabeleceu diferente e novos princípios [...] dentro dos diversos compartimentos [...] do Direito Civil. [...] sob o manto dos ideais que a fundam e que foram antepostos ao Estado, a nova Carta sacramenta, para a regência das relações privadas, noções éticas, sociais, políticas e econômicas [...]. Assim, as ideias de dignidade, liberdade, segurança, igualdade e justiça social, dentre outras, conduzirão a sociedade brasileira na busca de seus destinos e influenciarão, juridicamente, as reformas que se farão no plano da legislação ordinária.

Nesses termos, também é a lição de Pietro Perlingieri (2008, p. 33)

A tarefa hoje é contribuir para realizar, mediante uma renovada teoria da interpretação, axiologicamente orientada, uma justiça civil na legalidade constitucional e comunitária, utilizando os conteúdos e os valores característicos de tal legalidade não apenas na releitura de velhas e novas normas em nível ordinário, mas também na aplicação direta dos enunciados constitucionais

Nesta esteira, com o advento da Constituição como ápice do ordenamento jurídico e a irradiação de efeitos para todas as normas infraconstitucionais houve a necessidade de desenvolver mecanismos jurídicos para defesa deste importante documento normativo. Assim, fora desenvolvido a Jurisdição Constitucional, forma de exercício do poder que tem o escopo de resolver os conflitos que envolvam normas e princípios constitucionais.

Os conflitos existentes entre normas constitucionais são resolvidos, em determinados ordenamentos jurídicos, por órgãos diferenciados da jurisdição ordinária, para Favoreu (2004, p. 15) o contencioso constitucional deve ser resolvido por órgãos com exclusividade, situado fora do Poder Judiciário, independente deste e dos demais poderes, sendo denominados de Cortes Constitucionais. No Brasil, a jurisdição constitucional é exercida tanto por órgãos judiciais como pelo Supremo Tribunal Federal, configurando uma dupla maneira de 
proteção da constituição, portanto, como o conflito encontra-se em sede constitucional um dos órgãos competentes para resolver a contenda entre biógrafos e biografados é de competência do Supremo Tribunal Federal.

Como alhures demonstrado o conflito entre o direito de liberdade de expressão e a vida privada é ocasionado pela que necessidade de autorização do biografado para publicação de sua biografia por terceiros. Em decorrência da controvérsia entre jornalistas/editoras e personalidades públicas houve o ajuizamento de uma ação direta de inconstitucionalidade no Supremo Tribunal Federal, registrada sobre o n. 4.815/DF, de relatoria da Ministra Carmem Lúcia, versando sobre a inconstitucionalidade dos arts. 20 e 21, CC por afronta ao direito de liberdade de expressão e informação, ambos previstos no art. 5ª, IV, IX e XIV da Constituição Cidadã.

Deve-se ressaltar que na supracitada ação do controle concentrado não se questiona a inconstitucionalidade total dos dispositivos legais do Código Civil, mas sim a incompatibilidade parcial sem redução de texto de uma interpretação dada aos art. 20 e 21, CC por alguns órgãos do Poder Judiciário que proibiram a circulação de biografias não autorizadas, o legitimado ativo argumenta que se interpretando conforme a constituição a obrigatoriedade de autorização para publicação da biografia acarretaria uma inconstitucionalidade. Sobre a função da interpretação conforme a Constituição José Adércio Leite Sampaio (2013, p. 462) escreve que

Em sentido geral, determina-se que as normas legais sejam interpretadas de acordo com as normas constitucionais. Se houver dúvidas quanto à compreensão de um texto de lei, seja ela anterior ou posterior à promulgação constitucional, deve-se acolher aquele sentido que esteja em conformidade com a Constituição em vigor. A interpretação conforme, por conseguinte, serve para atualizar o sentido das leis anteriores à constituição [...] e corrige eventuais indeterminações dos textos posteriores a ela, dotando-os de coerência e sentido a partir do que determina a Constituição [...].

Assim, o que se persegue é a inaplicabilidade de um entendimento a respeito da norma legal e não sua extirpação do ordenamento jurídico pátrio, pois os dispositivos do Código Civil podem ser aplicados a outros fatos jurídicos, tal como o uso indevido de imagem de uma personalidade pública por uma empresa com fins lucrativos.

A demanda, que tramita sobre os ditames do controle abstrato de constitucionalidade foi ajuizada pela Associação Nacional dos Editores de Livros - ANEL e conta com inúmeros amicus curiae, tais como o Conselho Federal da Ordem dos Advogados do Brasil, Associação Eduardo Banks, Academia Brasileira de Letras, Artigo 19 Brasil, Instituto Histórico e Geográfico brasileiro, dentre outros.

Informa-se que o Supremo Tribunal Federal realizou audiência pública sobre a temática, fato que demonstra a complexidade que envolve o conflito. Impõem-se reconhecer que a utilização deste novel instrumento jurídico acarreta maior legitimidade para a decisão proferida pela Corte Suprema, pois esta estará 
fundada não somente na técnica, mas também em argumentos suscitados pelas partes interessadas, acarretando maior segurança jurídica ao controle abstrato de constitucionalidade.

Um dos principais argumentos do legitimado ativo que propôs a ação é de que os arts. 20 e 21, CC possibilitam uma espécie de censura privada por meio do Poder Judiciário, já que o dispositivo legal permite que o indivíduo ou seus familiares, em caso de falecimento do biografado, que tiver a divulgação de escritos, sem sua devida autorização, que afronte sua honra, boa fama, respeitabilidade ou tiver fins comerciais possa acionar o Poder Judiciário requerendo a proibição de circulação, requerendo, inclusive, indenização pecuniária caso tal veiculação afronte direito das personalidades.

Afirmam os defensores desta tese de que personalidades públicas com trajetória pessoal, política, profissional ou esportiva de relevo na sociedade detêm uma redução na sua esfera da vida privada e íntima, pois sua vida se confunde com a história coletiva da sociedade, sendo imprescindível para a sociedade a divulgação de fatos da sua vida para melhor compreensão ou influência de sua atuação na sociedade e/ou em movimentos sociais, artísticos ou literários.

Por seu turno, os que argumentam a favor da constitucionalidade dos dispositivos legais contidos na codificação civil entendem que eles, tão somente, são garantias para os indivíduos e que, também, detêm

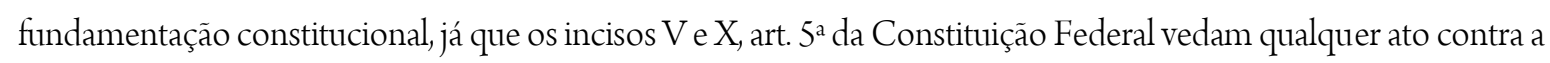
vida privada e íntima e, em que pese os atos da vida civil tenham algum relevo para a opinião pública há circunstancias que dizem respeito somente ao biografados e não a terceiros.

Ademais, um argumento que é suscitado sobre esta celeuma é referente ao benefício econômico que a comercialização da obra acarretará ao autor e editor da biografia, sendo este, na verdade, porém nunca admitido, o principal interesse sobre a questão das biografias não autorizadas, pois a quantidade de unidades vendidas sobre determinada personalidade do ramo musical, literário, político ou esportivo pode alcançar níveis econômicos estratosféricos, não sendo repassado qualquer valor ou participação para a figura do biografado, já que este não autorizou a veiculação de suas informações pessoais, logo, não terá participação nos dividendos auferidos com a veiculação de atos da sua vida privada.

Destarte, o que se verifica é que há argumentos legítimos para ambas as partes interessadas, sejam aqueles que querem exercer o direito de liberdade de expressão ou aqueles que querem omitir determinadas situações de sua vida privada, mesmo que essas possam ser de relevante interesse público.

A restrição (necessidade de autorização) imposta pelo Código Civil à liberdade de expressão configurase como uma lei restritiva ao direito fundamental, todavia, para que esta seja constitucional deve, segundo Canotilho (2003, p. 451) preencher seis requisitos, quais sejam:

1. Tratar-se de uma lei formal e organicamente constitucional? 
2. Existe autorização expressa da Constituição para o estabelecimento de limites através da lei?

3. A lei restritiva tem caráter geral e abstrato?

4. A lei restritiva tem efeitos retroativos?

5. A lei restritiva observa o princípio da proibição do excesso, estabelecendo as restrições necessárias para a salvaguarda de outros direitos ou interesses constitucionalmente protegidos?

6. A lei restritiva diminui a extensão e alcance do conteúdo essencial dos preceitos constitucionais?

A questão, porém, se encontra sob a responsabilidade do Supremo Tribunal Federal, onde, atualmente, todas as questões importantes para a sociedade brasileira se encontram sendo resolvidas, já que o Congresso Nacional se omite em tomar partido a respeito de qualquer controvérsia social.

Em Junho de 2015, o Supremo Tribunal Federal julgou a ação direta de inconstitucionalidade ajuizada sobre esta questão. A ministra relatora Carmem Lúcia (, ao cotejar os artigos da Constituição federal (arts. 5a , IV, V, IX, X, XIV e 220) com do Código Civil (arts. 20 e 21) suscita os caminhos que a Corte Suprema brasileira pode adotar no caso em debate:

Poder-se-ia concluir serem inconstitucionais as regras do Código Civil por proibirem divulgação de escritos, transmissão da palavra, publicação, exposição ou utilização da imagem de uma pessoa sem exceção a obras biográficas, exorbitando, no caso, de conteúdo que pode cercear ou até mesmo esvaziar liberdade constitucional de outrem?

$\mathrm{Ou}$, diversamente, haveria de se concluir serem constitucionais aquelas regras exatamente por serem regras que desdobram aqueles princípios com realce a direitos individuais, sem conflito substantivo, pelo que poderia ser ultrapassado mantendo-se o espaço de decisão particular do interessado? Ou, ainda, o conflito aparente de normas pode ser desfeito pela harmonização interna dos princípios e preceitos constitucionais, segundo os quais haverá de ser interpretada a legislação infraconstitucional, não se descurando a interpretação do texto considerado em seu contexto, sem o que a Constituição não seria mais que pretexto anulador de avanços sociais e jurídicos? (Brasília, 2015)

No conflito entre os princípios constitucionais supracitado houve, com fundamentação na interpretação conforme a Constituição sem redução do texto dos arts. 20 e 21, CC, a prevalência, nesta demanda, da liberdade de expressão, permitindo-se que sejam publicadas biografias mesmo sem quaisquer autorizações da personalidade retratada ou de seus sucessores, com a possibilidade de reparação civil em virtude de eventuais danos pela conduta do biógrafo.

Pelo método interpretativo da interpretação conforme a Constituição, na lição de Bastos (2014, p. 195)

Pela interpretação conforme a Constituição, uma lei não deve ser declarada nula quando seja passível de uma interpretação que a coloque em plena sintonia com o conjunto normativoconstitucional. Quando uma norma infraconstitucional apresentar dúvidas em relação ao seu significado, deve dar-se preferência à interpretação que the coloque em conformidade com os preceitos constitucionais. 
Neste sentido, atualmente, deve-se interpretar os arts. 20 e 21, CC de maneira que não se impõem a necessidade da autorização do biografado, importando o destaque à comparação realizada pela Ministra Relatora no tocante à intimidade e privacidade de pessoas públicas, após a indicação de julgados da Corte Europeia de Direitos Humanos relacionados à fatos ligados à intimidade e vida privada de Caroline Von Hanover, princesa de Mônaco:

A notoriedade tem preço: ele é fixado pela extensão da fama. E essa é quase sempre buscada. E quando não é, mas ainda assim é obtida, cobra pedágio: é o bilhete do reconhecimento público que se traduz em exposição do espaço particular, no qual querem adentrar todos. (BRASIL, 2015).

Contudo, em que pese os argumentos doutrinárias e as decisões que fundamentam a decisão do Supremo Tribunal Federal, esta tomada de decisão do Pretório Excelso, já era criticada por Anderson Schreiber (2013, p. 457) que ao se privilegiar de forma intransigente a liberdade de expressão causa detrimento do direito à privacidade e vida íntima.

Uma autorização genérica para expor sem qualquer limitação ou cuidado a intimidade de uma pessoa (famosa ou não) significaria suprimir o exercício de um direito fundamental que se mostra cada vez mais vulnerável na sociedade contemporânea: a privacidade. [...] devendo a necessária segurança ser buscada não em uma solução categórica - como fez o STF - que penda unicamente para um dos lados da balança, mas na identificação das circunstâncias relevantes para a ponderação dos interesses em conflito.

Contudo, ressalvou a Corte Suprema brasileira que em caso de afronta à direito das personalidades (honra, imagem, reputação ilibada, dentre outros), posteriormente pode o biografado ou seus sucessores requerer reparação civil por eventuais difamações ou injúrias contidas no texto.

Em que pese o posicionamento adotado pelo Supremo Tribunal Federal nesta questão relacionada ao tema, impõem, ainda, indicar uma proposição constitucionalmente adequada possa compatibilizar a questão referente a ambos os direitos fundamentais em conflito, pois mesmo com a reparação posterior de eventuais danos haverá a possibilidade de ajuizamentos de ações judiciais visando impedir que supostos escritos difamadores possa ser suprimidos de eventuais novas edições do texto, retornando-se à questão da censura privada ao estágio inicial.

\section{PROPOSIÇÃO CONSTITUCIONALMENTE MAIS ADEQUADA PARA RESOLUÇÃO DO CONFLITO NO CASO DAS BIOGRAFIAS NÃO AUTORIZADAS}

Conflitos entre direitos fundamentais, na Constituição Federal de 1988, são, relativamente, normais. O juiz constitucional tem que fazer um esforço hermenêutico hercúleo para compatibilizar os direitos existentes na Constituição Federal, pois invariavelmente previsões que veiculam direito à vida entram em conflito com o direito à morte digna, assim como o direito de propriedade e o direito à moradia e do direito de livre iniciativa e proteção ao trabalhador, dentre inúmeros outros. Luís Roberto Barroso (2011, p. 329) afirma que a colisão de direitos 
fundamentais decorre da "[...] complexidade e o pluralismo das sociedades modernas levaram ao abrigo da Constituição valores, interesses e direitos variados que eventualmente entram em choque".

Portanto, a colisão entre liberdade de expressão e inviolabilidade da vida íntima é só mais uma dentre inúmeras contendas entre direitos fundamentais e a manifestação livre do pensamento. Adverte-se que o direito de liberdade de expressão entra, constantemente, em colisão com outros direitos fundamentais não só no Brasil, mas em outros ordenamentos jurídicos, tendo o Tribunal Constitucional Alemão julgados inúmeros casos relacionados aos exercício da liberdade de expressão, tais como Lüth-Urteil, Schmid-Spiegel, Blinkfüer, Solidaritätsadresse, "Soldaten sind Mörder", Parabolantenne, Spiegel-Urteil, Benetton/Schockwerbung, Tendenzbetrieb, dentre outros, mencionados na coletânea de Jürgen Schwabe (2005, p. 379-461).

No Brasil, na esteira do posicionamento de Walter Claudius Rothenburg (2014, p. 155) quando há conflito entre direito de informação e a privacidade, se houver relevante interesse público, o Supremo Tribunal Federal tem um posicionamento de privilegiar a vida íntima do indivíduo em detrimento da liberdade de expressão, fato este comprovado com a decisão da Suprema Corte que julgou constitucional a determinação legal que prevê a exibição da remuneração dos servidores públicos em sítios na rede mundial de computadores.

As questões conflitantes entre direitos fundamentais, invariavelmente, devem ser resolvidas pelo critério da proporcionalidade, pois na lição de Barroso (2011, p. 333) as colisões entre direitos fundamentais têm a peculiaridade de não adequação aos critérios tradicionais de solução de antinomias, inadequação do método da subsunção e a necessidade de ponderação para encontrar o resultado constitucionalmente adequado para a colisão.

Sobre a proporcionalidade insta destacar que segundo Walter Claudius Rothenburg (2008, p. 291) a proporcionalidade não é um princípio constitucional - em que pese tenha se tornado comum, tanto na doutrina como na jurisprudência, esta adjetivação -, mas sim uma forma de resolução de conflitos entre direitos fundamentais, pois a proporcionalidade "nada diz sobre um valor fundamental projetado no ordenamento jurídico, apenas se dirige a relações que se estabelecem entre normas jurídicas de conteúdo material”. Corrobora este entendimento a lição de Luís Vírgilio Afonso da Silva (2002, p. 25)

O chamado princípio da proporcionalidade não pode ser considerado um princípio, pelo menos não com base na classificação de Alexy, pois não tem como produzir efeitos em variadas medidas, já que é aplicada de forma constante, sem variações. Assim, a proporcionalidade teria o caráter de regra jurídica, não de princípio.

Portanto, por meio do critério da proporcionalidade pode-se chegar ao modo de compatibilização entre os princípios da liberdade de expressão e da inviolabilidade da vida íntima, contudo, para se chegar a uma resposta constitucionalmente adequada o interprete deve ultrapassar os três estágios que compõem o critério da proporcionalidade, quais sejam; adequação, necessidade e proporcionalidade em sentido estrito. 
Segundo Walter Claudius Rothenburg (2014, p. 98) a adequação, também, denominada de idoneidade e conformidade é "A capacidade de proporcionar o alcance do objetivo pretendido ou pelo menos contribuir para tanto".

Por sua vez, a necessidade, no escólio de Humberto Ávila (2012, p. 192) consiste na:

Verificação da existência de meios que sejam alternativos àquele inicialmente escolhidos pelo Poder Legislativo ou Poder Executivo, e que possam promover igualmente o fim sem restringir, na mesma intensidade, os direitos fundamentais afetados.

Por derradeiro, a proporcionalidade em sentido estrito configura-se, na lição de Anizio Pires Gavião Filho (2011, p. 249) como o:

O lugar da ponderação e diz com cumprimento do mandamento de otimização conforme as possibilidades jurídicas. Este princípio parcial se deixa formular como a primeira lei da ponderação ou lei da ponderação material e que diz que quanto mais alto é o grau de não cumprimento ou prejuízo de um princípio, tanto maior deve ser a importância do cumprimento do outro.

Aplicando-se ao conflito entre liberdade de expressão e inviolabilidade da vida privada esses subcritérios da proporcionalidade deve-se concluir pela constitucionalidade ou não da autorização para publicação de biografias.

Quanto à adequabilidade da necessidade de autorização para publicação de biografias, entende-se que não é razoável quanto o texto do biógrafo tratar exclusivamente de atividade profissional, contudo, quando houver fatos da vida privada da personalidade pública a necessidade de autorização é adequada, tendo em vista que as particularidades de cada indivíduo são protegidas pelo ordenamento jurídico.

Em relação ao subcritério da necessidade, há razão ao legislador de impor um óbice ao livre exercício da liberdade de expressão dos biógrafos, já que tem o escopo de coibir abusos que possam causar prejuízos as personalidades públicas. Todavia, entende-se desproporcional a necessidade de chancela quando se tratar de escrito que veicula fatos ocorridos com exclusividade no âmbito profissional do indivíduo.

Por fim, a proporcionalidade em sentido estrito é uma ponderação entre os dois princípios constitucionais. É neste estágio que o interprete deve fazer um sopesamento e verificar as benesses e os prejuízos decorrentes da restrição ao direito fundamental, visando encontrar uma solução justa ao conflito sem acarretar danos aos direitos fundamentais colidentes.

Destarte, fazendo-se um juízo de ponderação e visando privilegiar ao máximo tanto a liberdade de expressão e a inviolabilidade da vida privada, realiza-se uma cisão fática no tema das relações das biografias não autorizadas, se o texto fizer menção à atividade profissional desenvolvida pela personalidade pública, tal qual a influência, por exemplo, de Sílvio Santos na comunicação brasileira, prestigia-se a liberdade de expressão em detrimento da inviolabilidade da vida privada, todavia, se o escrito abordar questóes relacionadas à intimidade da personalidade pública, a liberdade de expressão deve ceder em prol da observância da proteção constitucional da vida privada. 
Nesses termos é a lição de Anderson Schreiber (2013, p. 457) que corrobora a opinião exposta.

Trata-se de um conflito delicadíssimo, cuja solução não pode ser encontrada em termos absolutos, com a afirmação de que a liberdade prevalece sobre a privacidade, ou vice-versa, só porque a pessoa é ou deixa de ser famosa. A solução deve ser buscada na ponderação entre esses dois direitos fundamentais, prevalecendo ora a privacidade, ora a liberdade de expressão, diante das circunstancias relevantes de cada caso concreto. $\mathrm{O}$ que os juristas tem feito, em todo o mundo, é tentar identificar de antemão quais são essas circunstâncias relevantes, de modo a dar segurança a esse gênero literário. Por exemplo, tem-se concluído que, se o fato íntimo já foi divulgado na mídia em momento pretérito, essa circunstância é relevante para a solução do conflito, que possa pender em favor da liberdade de expressão, uma vez que aquele acontecimento já foi levado ao público passado. Diversamente, se o fato nunca foi revelado, cresce a importância de se tutelar a privacidade em relação a este fato específico mantido até então em sigilo.

Assim, observando os subcritérios que compõem a proporcionalidade, propõem-se que a controvérsia relacionada aos direitos de biógrafos e biografados e entre os direitos fundamentais já exaustivamente citados seja compatibilizada da seguinte maneira: os escritos devem ser relacionados tão somente com a atividade profissional exercida pela personalidade pública, sendo inconstitucional a autorização para esta manifestação da expressão, não necessitando de autorização, pois essas informações podem ser adquiridas em documentos públicos ou notícias veiculados pela imprensa.

Entende-se que quanto à atuação profissional a inconstitucionalidade da autorização persiste, pois a compilação da atuação desta personalidade pública em um livro pode influenciar a forma como a sociedade ver ou reconhece determinado segmento profissional propiciando o desenvolvimento e a propagação do conhecimento ou determinada atividade lúdica ou esportiva, fato que elevou o direito de liberdade de expressão ao status constitucional. Ademais, obstar a propagação e o desenvolvimento de um conhecimento a vontade de uma única pessoa não se coaduna com os ditames da uma sociedade justa, livre e solidária.

Contudo, quando a intenção do biógrafo for relacionada a assuntos particulares do biografado, sem qualquer vinculação com a atuação profissional de relevante interesse social e sem qualquer influencia em determinado segmento do conhecimento há que se proteger a vida privada deste, incidindo, assim, toda a proteção constitucional da personalidade humana, exigindo-se sua autorização para veicular fatos de sua intimidade, pois somente com o depoimento do biografado é que se pode alcançar a verdade dos fatos e a razão de determinado comportamento daquela personalidade pública em algum momento de sua existência, algo inatingível se não houver a colaboração daquele que se esta contando a história de vida. Relembra-se que o direito à liberdade e expressão esta limitado à verdade dos fatos, não podendo ser veiculados fatos que desvinculados da realidade dos fatos.

Ademais, caso o texto do biógrafo seja difamatório ou de alguma maneira infrinja ou cause prejuízos à honra da personalidade pública deve haver a condenação na reparação civil e supressão da parcela da obra que cause danos ao biografado, inadmitindo-se a veiculação total da obra. 
Por fim, defende-se que os ganhos pecuniários obtidos com a comercialização da obra sejam repartidos com a personalidade pública, pois a própria Constituição protege o uso da imagem dos indivíduos, assim, no julgamento do leading case deve-se prever parâmetros percentuais de distribuição dos dividendos ao biografado com base no número de edições vendidas ao público, possibilitando-se que caso ocorra controvérsias quanto aos valores, o juiz de primeira instancia possa rever o percentual do repasse pecuniária ao biografado limitados aos parâmetros estabelecidos na decisão judicial.

Entende-se que desta maneira haveria uma compatibilização dos variados interesses relacionados a questão das biografias não autorizadas, prestigiando-se ambos os direitos fundamentais, o da liberdade de expressão e o da inviolabilidade da intimidade, ora um direito fundamental sendo aplicado, ora outro cedendo espaço, havendo uma reciprocidade mútua de interesse para ambas as partes que estabelecidas as premissas necessárias para exercício do direito fundamental poderão exerce-lo sem o receio de encontrar-se realizando um ato ilícito.

\section{CONCLUSÃO}

Quando se trata da temática referente a conflitos entre direitos constitucionalmente garantidos não há uma resposta objetiva pronta que se aplique a inúmeros fatos jurídicos de maneira semelhante, o julgador, investido no poder/dever de proteção da Constituição deve ponderar vários argumentos até que se encontre uma resposta viável para o antagonismo, sem que ocorra ofensas, desrespeito ou extinção da norma ou princípio constitucional inaplicado.

Na questão de fundo deste ensaio, defende-se que a liberdade de expressão do biógrafo deve ser restrita à atividade pública-profissional exercida pela personalidade pública, desde que respeitado determinados limites, tais como o escrito encontrar-se fundado em documentos, notícias ou testemunhos de pessoas ligados às áreas de atuação da personalidade pública, que não causem prejuízos à honra e imagem do biografado.

Contudo os aspectos ligados à vida íntima sem qualquer influência com a atividade profissional, artística ou pública exercida pela personalidade de relevo na sociedade encontram-se protegidos pelas previsões constitucionais, não podendo haver interferências sem autorização. Convenhamos que saber as razões e os sofrimentos causados pela perna do cantor Roberto Carlos ou os fatos que ocorreram após a perda de um dedo pelo ex-presidente Luis Inácio Lula da Silva não interferem em nada nos papeis sociais realizados por este na sociedade, não sendo fatos que possam ser veiculados sem a autorização da personalidade pública, até porque as únicas pessoas que possam passar uma mensagem fidedigna com a realidade é a própria personalidade pública, faltando com o dever da verdade, pois nenhum relato de terceiro terá a capacidade de transmitir a realidade dos fatos da maneira correta. 
Portanto, não se adota a posição declarada pelo Supremo Tribunal Federal de que os arts. 20 e 21, CC devam ser interpretados conforme a Constituição de maneira a privilegiar a liberdade de expressão em detrimento da violabilidade da vida intima e privada, pois esses dois princípios também se encontram constitucionalmente previstos, devendo-se não privilegiar apenas um, mas ambos, numa decisão que pudesse resguardar, tantos os direitos dos biógrafos como dos biografados.

Todavia, a controvérsia a respeito das biografias não autorizadas é somente um exemplo entre conflitos de direitos fundamentais, na própria relação entre liberdade de expressão versus intimidade. Diversos conflitos surgirão com o desenvolvimento das tecnologias e o uso de redes sociais, devem o juiz constitucional encontrar-se apto para resolução dessas noveis relações sem as restrições impostas pela lei, possibilitando que, sempre à luz do caso concreto, possa se privilegiar ora a liberdade de expressão, ora o direito de inviolabilidade da vida privada.

\title{
UNAUTHORIZATION BIOGRAFHIES: CONFLICT BETWEEN FREEDOM OF SPEECH AND INVIOLABILITY OF PRIVACY LIFE
}

\begin{abstract}
The issue addressed in this paper concerns the conflict of fundamental rights on the one hand the right to freedom of expression and the right opposite the honor and the sanctity of private life. Focus on this issue exists because of the national laws controversy as to attempt to publications of unauthorized biographies of public personality biographers, a fact that causes disputes between private and must be pacified. In the meantime, addresses the issue of fundamental rights of freedom of expression and inviolability of private life and private in the Federal Constitution of 1988, addressing the question of the applicability of fundamental rights in private relations. We study the direct action of unconstitutionality pending in the Supreme Court regarding the issues raised since there are legal arguments in the sense that the Civil Code holds device that possibly affront the right to freedom of expression, as well as propose a way be followed for the better resolution of the impasse between freedom of expression and the right to biographers sanctity of life intimacy of biography. The methodology used to work out the deductive, with analysis of jurisprudence and doctrine on the case
\end{abstract}

Keywords: Freedom of Speech; Private Life; Fundamental Rigths; Proportionality

\section{REFERENCIAS}

ARAUJO, Luiz Alberto David. NUNES JÚNIOR, Vidal Serrano. Curso de Direito Constitucional. $16^{\circ}$ ed. São Paulo: Verbatim, 2012.

ÁVILA, Humberto. Teoria dos Princípios: Da definição à aplicação dos princípios jurídicos. $13^{\circ} \mathrm{ed}$. rev. e ampl. São Paulo: Malheiros, 2012. 
BARROSO, Luís Roberto. Curso de Direito Constitucional Contemporâneo: Os conceitos fundamentais e a construção do novo modelo. $2^{2}$ ed. Saraiva: São Paulo, 2011.

BASTOS, Celso Ribeiro. Hermenêutica e Interpretação Constitucional. 4a ed. rev. e atual. São Paulo: Malheiros, 2014.

BITTAR, Carlos Alberto. BITTAR FILHO, Carlos Alberto. Direito Civil Constitucional. 3a ed. São Paulo: 2003.

BRASIL. SUPREMO TRIBUNAL FEDERA. AÇÃO DIRETA DE INCONSTITUCIONALIDADE $\mathrm{n}$. 4.815/DF. Relatora: LÚCIA, Carmem. Disponível em: < http://redir.stf.jus.br/estfvisualizadorpub/jsp/consultarprocessoeletronico/ConsultarProcessoEletronico.js? seq objetoincidente $=4271057>$ Acesso em: 13.10.2015.

CANOTILHO, José Joaquim Gomes. Direito Constitucional e Teoria da Constituição. 7a ed. Coimbra: Almedina, 2003.

DIMOULIS, Dimitri. MARTINS, Leonardo. Teoria Geral dos Direitos Fundamentais. $4^{a}$ ed. rev. ampl. São Paulo: Atlas, 2012.

FAVOREU, Louis. As Cortes Constitucionais. São Paulo: Landy, 2004.

GAVIÃO FILHO, Anizio Pires. Colisão de Direitos Fundamentais, argumentação e ponderação. Porto Alegre: Livraria do Advogado, 2011.

KOATZ, Rafael Lorenzo-Fernandez. As Liberdades de Expressão e de Imprensa na Jurisprudência do STF. In SARMENTO, Daniel. SARLET, Ingo Wolfgang (ORG). Direitos Fundamentais no Supremo Tribunal Federal: Balanço e Crítica Rio de Janeiro: Lumen Juris, 2011

MÄDER, Nicole P. S. Gonçalves. Liberdade de Expressão e Estado Democrático de Direito. In CLÈVE, Clèmerson Merlin (ORG). Direito Constitucional Brasileiro: Teoria da Constituição e Direitos Fundamentais. São Paulo: Revista dos Tribunais, 2014.

MENDES, Gilmar Ferreira. BRANCO, Paulo Gustavo Gonet. Curso de Direito Constitucional. $7^{\circ}$ ed. São Paulo: Saraiva, 2012.

ROTHENBURG, Walter Claudius. Direitos Fundamentais. São Paulo: Método, 2014.

O Tempero da Proporcionalidade no Caldo dos Direitos Fundamentais. In OLIVEIRA NETO, Olavo. LOPES, Maria Elizabeth de Castro. Princípios Processuais Civis na Constituição. Rio de Janeiro: Elsevier, 2008.

SAMPAIO, José Adércio Leite. Teoria da Constituição e dos Direitos Fundamentais. Belo Horizonte: Del Rey, 2013.

SARLET, Ingo Wolfgang. A Eficácia dos Direitos Fundamentais: Uma Teoria Geral dos Direitos Fundamentais na Perspectiva Constitucional. $11^{\circ} \mathrm{ed}$, rev e atual. Porto Alegre: Livraria do Advogado, 2012.

SCHREIBER, Anderson. Direito Civil e Constituição. São Paulo: Atlas, 2013. 
SCHWABE, Jürgen. Cinquenta Anos de Jurisprudência do Tribunal Constitucional Federal Alemão. Fundación Konrad-Adenauer: Montevideo, 2005.

SILVA, Luís Virgílio Afonso da. O proporcional e o razoável. Revista dos Tribunais: São Paulo, n. 798, p. 23-50, abr. 2002.

PERLINGIERI, Pietro. O Direito Civil na Legalidade Constitucional. Renovar: São Paulo, 2008.

Trabalho enviado em 30 de agosto de 2015.

Aceito em 20 de novembro de 2015. 